Special issue in honour of Prof. Reto J. Strasser

\title{
Photoinhibition of oxygen-evolving complex and photosystem II at chilling stress in the tropical tree species Dalbergia odorifera
}

\author{
Y.-J. YANG*, T. LIU ${ }^{* *}$, S.-B. ZHANG*, and W. HUANG ${ }^{*, * * *,+}$ \\ Key Laboratory of Economic Plants and Biotechnology, Kunming Institute of Botany, Chinese Academy of Sciences, \\ 650201 Kunming, Yunnan, China* \\ National and Local Joint Engineering Research Center on Germplasm Utilization and Innovation of Chinese \\ Medicinal Materials in Southwest China, Yunnan Agricultural University, 650201 Kunming, Yunnan, China** \\ Key Laboratory of Tropical Forest Ecology, Xishuangbanna Tropical Botanical Garden, Chinese Academy \\ of Sciences, 666303 Mengla, Yunnan, China ${ }^{* * *}$
}

\begin{abstract}
Photosystem II is sensitive to chilling stress in tropical tree species. However, the underlying mechanism is not clear. In this study, we examined the effects of chilling and light stress on activities of PSII and oxygen-evolving complex (OEC), in order to resolve the controversy of whether chilling-induced PSII photoinhibition is attributed to the excess-energy model or the two-step scheme. We determined changes in chlorophyll $a$ fluorescence transient and energy distribution in PSII during treatment at chilling-light stress for the tropical tree species Dalbergia odorifera. At chilling temperature, the lightuse efficiency was largely inhibited. During chilling treatment, the maximum quantum yield of PSII gradually decreased. Meanwhile, the relative fluorescence intensity at K-step (300 $\mu$ s) significantly increased, indicating the photodamage to OEC. A tightly positive correlation was found between photodamage to OEC and PSII photoinhibition, suggesting that photodamage to OEC was a rate-limiting step for PSII photoinhibition. Furthermore, additional generation of reactive oxygen species did not aggravate PSII photoinhibition at chilling temperature. These results suggest that two-step model is responsible for chilling-induced PSII photoinhibition in the tropical tree species D. odorifera.
\end{abstract}

Additional key words: chlorophyll fluorescence; JIP-test; low temperature; photosynthesis.

\section{Introduction}

Chilling temperatures above zero are the major limitation to the distribution of tropical plants at higher latitudes and altitudes. Due to the exacerbation of tropical forest fragmentation and increasing demand on tropical hardwood timber, forestation using tropical high-quality timber species in marginal tropical areas is presently under practice. Occasionally, cold snaps invade these areas for several days and cause severe damage to the introduced tropical crops and plants. Our previous studies indicated that chilling temperature associated with moderate light intensity caused strong photodamage to PSII but little photodamage to PSI in tropical tree species (Huang et al. 2010a,b), similar to pumpkin, spinach (Barth and Krause 1999), and Paphiopedilum species (Yang et al. 2017).
However, the underlying mechanism of chilling-induced photoinhibition of PSII in tropical tree species is not well known.

Light is the driving power of photosynthesis. However, excess light energy absorbed by leaves, being neither utilized by photochemistry nor dissipated harmlessly as heat by nonphotochemical quenching, induces the generation of reactive oxygen species (ROS), which could induce photoinhibition of PSII. At present, there are two proposed schemes to explain the molecular mechanism of photoinhibition of PSII. In the excess-energy scheme, photodamage of PSII is a one-step process: ROS cause direct oxidative damage to PSII complexes (Vass et al. 1992, Telfer et al. 1994, Okada et al. 1996, Chow and Aro 2005, Krieger-Liszkay et al. 2008, 2011; Vass 2011). However, the more recent two-step scheme demonstrates

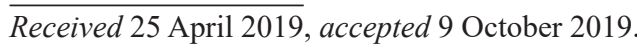

${ }^{+}$Corresponding author; phone: +86-871-65223112, e-mail: huangwei@mail.kib.ac.cn

Abbreviations: $\mathrm{F}_{\mathrm{t}}$ - fluorescence level at time $\mathrm{t} ; \mathrm{F}_{\mathrm{v}} / \mathrm{F}_{\mathrm{m}}-$ maximum quantum yield of PSII after dark adaptation; $\mathrm{F}_{\mathrm{v}}{ }^{\prime} / \mathrm{F}_{\mathrm{m}}{ }^{\prime}-\mathrm{maximum}$ quantum yield of PSII after light adaptation; MV - methyl viologen; $\mathrm{q}_{\mathrm{P}}$ - photochemical quenching coefficient; ROS - reactive oxygen species; $V_{K}$ - relative variable fluorescence at $300 \mu \mathrm{s} ; \mathrm{W}_{\mathrm{K}}$ - the ratio of variable fluorescence $\mathrm{F}_{\mathrm{K}}$ to the amplitude $\mathrm{F}_{\mathrm{J}}-\mathrm{F}_{0} ; \mathrm{V}_{\mathrm{t}}-$ relative variable fluorescence at time t; $Y_{(I I)}$ - effective quantum yield of PSII photochemistry; $Y_{(\mathrm{NO})}$ - quantum yield of nonregulated energy dissipation in PSII; $\mathrm{Y}_{(\mathrm{NPQ})}$ - quantum yield of regulated energy dissipation in PSII via nonphotochemical quenching.

Acknowledgements: This work was supported by National Natural Science Foundation of China $(31300332,31860075)$ and Yunnan Applied Basic Research Project (2017FG001). 
that the primary photodamage to PSII occurs at the oxygenevolving complex (OEC) with release of manganese ions $\left(\mathrm{Mn}^{2+}\right)$ (Hakala et al. 2005, Zsiros et al. 2006, Antal et al. 2009, Murata et al. 2012). The disruption of the manganese cluster upon absorption of light is a primary event in photodamage (Tyystjärvi 2008, Zavafer et al. 2015, 2017). Following photodamage to OEC, the supply of electrons from water to the primary electron donor of PSII $\left(\mathrm{P}_{680^{+}}{ }^{\bullet}\right)$ is blocked, and, as a result, the level of $\mathrm{P}_{680}{ }^{+}$remains high (Murata et al. 2007, Takahashi and Murata 2008, Takahashi and Badger 2011). $\mathrm{P}_{680}{ }^{+}$is a strong oxidant and at high levels might damage the PSII reaction centers (Takahashi and Murata 2008). Furthermore, in the two-step scheme, ROS inhibit the repair of photodamaged PSII but do not aggravate the rate of photodamage (Nishiyama et al. 2001, 2004, 2005, 2006, 2011; Allakhverdiev and Murata 2004, Takahashi et al. 2009). Interestingly, Oguchi et al. (2011) suggest that both mechanisms lead to photodamage of PSII under high light, the underlying mechanism of PSII photodamage in higher plants is largely controversial (Murata et al. 2012, Vass 2012).

Net PSII photoinhibition occurs only when the rate of PSII photodamage exceeds the rate of recovery. At chilling temperature, the linear electron flow was largely inhibited (Huang et al. 2011, 2016a; Yang et al. 2018), resulting in inhibition of ATP synthesis (Huang et al. 2017). Consequently, the ATP-dependent fast de novo synthesis of D1 protein was largely inhibited at chilling temperature (Allakhverdiev and Murata 2004). Therefore, the extent of PSII photoinhibition at chilling stress is mainly determined by the rate of PSII photodamage. According to the excessenergy scheme, singlet oxygen generated in PSII damages the D1 protein of PSII (Vass 2011). In the addition of methyl viologen, which accepts electrons from PSI to $\mathrm{O}_{2}$, superoxide anion radicals damage PSII in isolated thylakoids of tobacco (Krieger-Liszkay et al. 2011). By comparison, at chilling temperature, visible light damages OEC prior to photodamage to the PSII reaction center in isolated PSII membrane fragments of spinach (Zavafer et al. 2015, 2017). As a result, the mechanisms of PSII photoinhibition induced by chilling-light stress have not yet been clarified.

To test the scheme, which is responsible for the chilling-induced photoinhibition of PSII in the tropical tree species Dalbergia odorifera, we determined the effects of chilling-light stress on photodamage of PSII and OEC by measurements of chlorophyll (Chl) a fluorescence transient and light-adapted $\mathrm{Chl}$ fluorescence. The following questions were addressed: (1) Is photodamage to OEC a rate-limiting step for PSII photoinhibition? (2) Do additional ROS accelerate PSII photoinhibition at chilling temperature?

\section{Materials and methods}

Plant materials and growth conditions: The chillingsensitive tropical tree Dalbergia odorifera T. Chen (Fabaceae) is a light-demanding tree species occurring in secondary forests and is native to the Hainan Island, China. It produces high-quality timber. Sun leaves represent the leaves of 3-year-old seedlings grown in an open site with full sunlight. Shade leaves represent the leaves of 2-yearold seedlings grown under a shaded environment with $10 \%$ sunlight controlled by a shade net. These seedlings were cultivated under good water and nutrition conditions. They exhibit good growth in Xishuangbanna Tropical Botanical Garden $\left(21^{\circ} 54^{\prime} \mathrm{N}, 101^{\circ} 46^{\prime} \mathrm{E}\right.$, and altitude $\left.570 \mathrm{~m}\right)$ located in the northern boundary of tropical zone. The highest PPFD at midday is up to $1,850 \mu \mathrm{mol}$ (photon) $\mathrm{m}^{-2} \mathrm{~s}^{-1}$ in summer and $1,350 \mu \mathrm{mol}$ (photon) $\mathrm{m}^{-2} \mathrm{~s}^{-1}$ in winter, respectively. Mean air temperatures are approximately $34 / 24^{\circ} \mathrm{C}$ (day/ night) in summer and $25 / 14^{\circ} \mathrm{C}$ (day/night) in winter.

Photoinhibitory treatment: Sun leaves on branches, which were immersed in water, were placed in a thermostatic $4^{\circ} \mathrm{C}$ chilling storage room and were illuminated under light (LED optical source, Chengdu Maiyue Technology Ltd., China). To examine the effect of chilling stress on OEC, Chl a fluorescence transient OKJIP was determined in sun leaves during chilling treatment at $4^{\circ} \mathrm{C}$ under a PPFD of $430 \mu \mathrm{mol}$ (photon) $\mathrm{m}^{-2} \mathrm{~s}^{-1}$. To examine the effect of ROS on PSII photodamage in D. odorifera illuminated at chilling temperature, detached shade leaves were vacuum infiltrated with either $\mathrm{H}_{2} \mathrm{O}$ or $300 \mu \mathrm{M}$ methyl viologen (MV) to promote electrons from PSI to $\mathrm{O}_{2}$ at $25^{\circ} \mathrm{C}$ for $1 \mathrm{~h}$ in darkness and then illuminated at $4^{\circ} \mathrm{C}$ for $2 \mathrm{~h}$ under a light of $430 \mu \mathrm{mol}$ (photon) $\mathrm{m}^{-2} \mathrm{~s}^{-1}$. MV can abolish cyclic electron flow by promoting electrons from PSI to $\mathrm{O}_{2}$. The effect of MV on PSII photodamage in sun leaves of D. odorifera includes at least two mechanisms: abolishing cyclic electron flow, and increasing production of ROS. Because cyclic electron flow activity was much lower in the shade leaves than that of the sun leaves (data not shown), the effect of MV on PSII photodamage in the shade leaves can be mainly interpreted by increasing generation of ROS. Therefore, we chose the shade leaves in order to examine the effect of ROS on PSII photodamage in D. odorifera illuminated at chilling temperature.

Chl fluorescence measurements: Chl $a$ fluorescence transient is a useful noninvasive technique to monitor and predict photosynthetic responses to various abiotic stresses (Li et al. 2009, Swoczyna et al. 2010, Dąbrowski et al. 2015, 2016, 2017; Mathur et al. 2016). In this study, Chl $a$ fluorescence transient was determined by a Dual-PAM100 (Heinz Walz, Effeltrich, Germany) after dark adaptation at $25^{\circ} \mathrm{C}$ for $30 \mathrm{~min}$. Each transient obtained from the dark-adapted samples was analyzed according to the JIPtest (Strasser et al. 2000, 2004; Kalaji et al. 2018): (1) the fluorescence intensity at $30 \mu \mathrm{s}\left(\mathrm{F}_{0}\right.$, when all reaction centers of PSII are open); (2) the maximum fluorescence intensity $\left(\mathrm{F}_{\mathrm{m}}\right.$, when all reaction centers of PSII are closed), and (3) the fluorescence intensities at $300 \mu$ s (K-step), $2 \mathrm{~ms}$ (J-step), and $30 \mathrm{~ms}$ (I-step).

The maximum quantum yield of PSII after dark adaptation was calculated as $\mathrm{F}_{\mathrm{v}} / \mathrm{F}_{\mathrm{m}}=\left(\mathrm{F}_{\mathrm{m}}-\mathrm{F}_{0}\right) / \mathrm{F}_{\mathrm{m}}$. The relative variable fluorescence intensity was calculated as $\mathrm{V}_{\mathrm{t}}=$ $\left(F_{t}-F_{0}\right) /\left(F_{m}-F_{0}\right)$, where $F_{t}$ is the fluorescence intensity at any time upon illumination with a pulse $[10,000$ $\mu \mathrm{mol}\left(\right.$ photon) $\mathrm{m}^{-2} \mathrm{~s}^{-1}$ and $\left.300 \mathrm{~ms}\right]$. The change in $\mathrm{V}_{\mathrm{t}}$ during 
chilling treatment compared with the control was calculated as $\Delta \mathrm{V}_{\mathrm{t}}=\left[\left(\mathrm{F}_{\mathrm{t}}-\mathrm{F}_{0}\right) /\left(\mathrm{F}_{\mathrm{m}}-\mathrm{F}_{0}\right)\right]_{\text {treatment }}-\left[\left(\mathrm{F}_{\mathrm{t}}-\mathrm{F}_{0}\right) /\left(\mathrm{F}_{\mathrm{m}}-\mathrm{F}_{0}\right)\right]_{\text {control }}$. In this study, $\left[\left(\mathrm{F}_{\mathrm{t}}-\mathrm{F}_{0}\right) /\left(\mathrm{F}_{\mathrm{m}}-\mathrm{F}_{0}\right)\right]_{\text {control }}$ represents the value of $\left(F_{t}-F_{0}\right) /\left(F_{m}-F_{0}\right)$ measured before chilling treatment. The ratio of variable fluorescence $F_{K}$ to the amplitude $\mathrm{F}_{\mathrm{J}}-\mathrm{F}_{0}\left(\mathrm{~W}_{\mathrm{K}}\right)$ was calculated as $\mathrm{W}_{\mathrm{K}}=\left(\mathrm{F}_{\mathrm{K}}-\mathrm{F}_{0}\right) /\left(\mathrm{F}_{\mathrm{J}}-\mathrm{F}_{0}\right)$.

The energy distribution in PSII was also determined by the Dual-PAM100. $\mathrm{F}_{0}$ and $\mathrm{F}_{\mathrm{m}}$ was determined after dark adaptation at $25^{\circ} \mathrm{C}$ for $30 \mathrm{~min}$. Leaves on detached branches were light adapted at $25^{\circ} \mathrm{C}$ and $430 \mu \mathrm{mol}$ (photon) $\mathrm{m}^{-2} \mathrm{~s}^{-1}$ for at least $20 \mathrm{~min}$. Afterwards, PSII parameters were measured at 25 and $4{ }^{\circ} \mathrm{C}$. The following chlorophyll fluorescence parameters were calculated: $\mathrm{F}_{\mathrm{v}} / \mathrm{F}_{\mathrm{m}}=\left(\mathrm{F}_{\mathrm{m}}-\mathrm{F}_{0}\right) / \mathrm{F}_{\mathrm{m}}$, $\mathrm{F}_{\mathrm{v}}{ }^{\prime} / \mathrm{F}_{\mathrm{m}}{ }^{\prime}=\left(\mathrm{F}_{\mathrm{m}}{ }^{\prime}-\mathrm{F}_{0}{ }^{\prime}\right) / \mathrm{F}_{\mathrm{m}}{ }^{\prime}, \mathrm{F}_{0}{ }^{\prime}=\mathrm{F}_{0} /\left(\mathrm{F}_{\mathrm{v}} / \mathrm{F}_{\mathrm{m}}+\mathrm{F}_{0} / \mathrm{F}_{\mathrm{m}}{ }^{\prime}\right)($ Oxborough and Baker 1997), $\mathrm{q}_{\mathrm{P}}=\left(\mathrm{F}_{\mathrm{m}}{ }^{\prime}-\mathrm{F}_{\mathrm{s}}\right) /\left(\mathrm{F}_{\mathrm{m}}{ }^{\prime}-\mathrm{F}_{0}{ }^{\prime}\right), \mathrm{Y}_{(\mathrm{II})}=$ $\left(\mathrm{F}_{\mathrm{m}}{ }^{\prime}-\mathrm{F}_{\mathrm{s}}\right) / \mathrm{F}_{\mathrm{m}}{ }^{\prime}\left(\right.$ Genty et al. 1989), $\mathrm{Y}_{(\mathrm{NPQ})}=\mathrm{F}_{\mathrm{s}} / \mathrm{F}_{\mathrm{m}}{ }^{\prime}-\mathrm{F}_{\mathrm{s}} / \mathrm{F}_{\mathrm{m}}$, $\mathrm{Y}_{(\mathrm{NO})}=\mathrm{F}_{\mathrm{s}} / \mathrm{F}_{\mathrm{m}}$ (Hendrickson et al. 2004, Kramer et al. 2004). $\mathrm{F}_{0}$ and $\mathrm{F}_{0}{ }^{\prime}$ are the dark-adapted and light-adapted minimum fluorescence. $\mathrm{F}_{\mathrm{m}}$ and $\mathrm{F}_{\mathrm{m}}{ }^{\prime}$ are the dark-adapted and lightadapted maximum fluorescence upon illumination with a pulse $(300 \mathrm{~ms})$ of saturating light $[10,000 \mu \mathrm{mol}$ (photon) $\mathrm{m}^{-2} \mathrm{~s}^{-1}$ ], respectively. $F_{\mathrm{s}}$ is the light-adapted steady-state fluorescence. $\mathrm{F}_{\mathrm{v}}{ }^{\prime} / \mathrm{F}_{\mathrm{m}}$ ' is the maximum quantum yield of PSII after light adaptation. The parameter $1-\mathrm{q}_{\mathrm{P}}$ can be used to indicate the excitation pressure in PSII or the proportion of closed PSII reaction centers. $Y_{\text {(II) }}$ is the effective quantum yield of PSII. $\mathrm{Y}_{(\mathrm{NPQ})}$ corresponds to the fraction of energy dissipated in form of heat via the regulated photoprotective NPQ mechanism. $Y_{(\mathrm{NO})}$ is the fraction of energy that is passively dissipated in form of heat and fluorescence. A high value of $Y_{(\mathrm{NO})}$ indicates that the excess light energy in PSII cannot be quenched by photochemistry and NPQ. All measured and calculated fluorescence parameters were listed in the text table.
Statistical analysis: The results were displayed as mean values of four independent experiments. One-way analysis of variance $(A N O V A)$ test was used at $\alpha=0.05$ significance level to determine whether significant differences existed between different treatments.

\section{Results}

Light-adapted PSII parameters: We first determined the light-adapted PSII parameters at 25 and $4{ }^{\circ} \mathrm{C}$. When shifted from 25 to $4^{\circ} \mathrm{C}$, the light-adapted maximum quantum yield of PSII $\left(\mathrm{F}_{\mathrm{v}}{ }^{\prime} / \mathrm{F}_{\mathrm{m}}{ }^{\prime}\right)$ significantly decreased at the chilling temperature of $4^{\circ} \mathrm{C}$ (Fig. $1 A$ ). The value of $1-\mathrm{q}_{\mathrm{p}}$ increased largely from 0.13 (at $25^{\circ} \mathrm{C}$ ) to 0.84 (at $4^{\circ} \mathrm{C}$ ) (Fig. $1 B$ ), indicating that the most of PSII reaction centers were closed at the chilling temperature of $4^{\circ} \mathrm{C}$. Because of the large decreases in $\mathrm{F}_{\mathrm{v}}{ }^{1} / \mathrm{F}_{\mathrm{m}}{ }^{\prime}$ and $\mathrm{q}_{\mathrm{P}}, \mathrm{Y}_{\text {(II) }}$ largely decreased from 0.63 (at $25^{\circ} \mathrm{C}$ ) to 0.10 (at $4^{\circ} \mathrm{C}$ ) (Fig. $1 \mathrm{C}$ ). These results suggest that the photosynthetic $\mathrm{CO}_{2}$ assimilation was strongly inhibited at the chilling temperature of $4^{\circ} \mathrm{C}$, which caused depression of $\mathrm{Y}_{(\mathrm{II})}$. The value of $\mathrm{Y}_{(\mathrm{NPQ})}$ (fraction of energy dissipated in form of heat via the regulated photoprotective NPQ mechanism) largely increased when transferred abruptly from 25 to $4^{\circ} \mathrm{C}$ (Fig. $1 D$ ), indicating that the activation of NPQ was a rapid photoprotective response at chilling temperature. The value of $\mathrm{Y}_{(\mathrm{NO})}$ slightly increased at $4^{\circ} \mathrm{C}$ when compared to $25^{\circ} \mathrm{C}$ (Fig. $1 E$ ). This increase in $\mathrm{Y}_{(\mathrm{NO})}$ indicates excess excitation energy in PSII that cannot be quenched by photochemistry and NPQ (Busch et al. 2009), thus increasing the risk of PSII photoinhibition during the chilling treatment.

Chl $\boldsymbol{a}$ JIP-test: Next, we measured the Chl $a$ fluorescence transient in order to examine the effects of chilling

\begin{tabular}{ll}
\hline Parameter & Name and basic physiological interpretation \\
\hline Basic values and JIP-test parameters from fast chlorophyll fluorescence induction \\
$\mathrm{F}_{\mathrm{t}}$ & Fluorescence level at time $\mathrm{t}$ \\
$\mathrm{F}_{0}=\mathrm{F}_{30 \mathrm{\mu s}}$ & Minimum fluorescence at O-step \\
$\mathrm{F}_{\mathrm{m}}=\mathrm{F}_{\mathrm{P}}$ & Maximum fluorescence at P-step \\
$\mathrm{V}_{\mathrm{t}}=\left(\mathrm{F}_{\mathrm{t}}-\mathrm{F}_{0}\right) /\left(\mathrm{F}_{\mathrm{m}}-\mathrm{F}_{0}\right)$ & Relative variable fluorescence at time $\mathrm{t}\left(\mathrm{V}_{\mathrm{K}}\right.$ at $\left.300 \mu \mathrm{s}\right)$ \\
$\mathrm{W}_{\mathrm{K}}=\left(\mathrm{F}_{\mathrm{K}}-\mathrm{F}_{0}\right) /\left(\mathrm{F}_{\mathrm{J}}-\mathrm{F}_{0}\right)$ & The ratio of variable fluorescence $\mathrm{F}_{\mathrm{K}}$ to the amplitude $\mathrm{F}_{\mathrm{J}}-\mathrm{F}_{0}$ \\
$\mathrm{Ch}_{0}$ lorophyll fluorescence parameters derived from the saturation pulse analysis \\
$\mathrm{F}_{0}$ & Minimum fluorescence after dark adaptation \\
$\mathrm{F}_{\mathrm{m}}, \mathrm{F}_{\mathrm{m}}{ }^{\prime}$ & Maximum fluorescence after dark or light adaptation respectively \\
$\mathrm{F}_{\mathrm{s}}$ & Steady-state fluorescence after light adaption \\
$\mathrm{F}_{\mathrm{v}} / \mathrm{F}_{\mathrm{m}}=\left(\mathrm{F}_{\mathrm{m}}-\mathrm{F}_{0}\right) / \mathrm{F}_{\mathrm{m}}$ & Maximum quantum yield of PSII photochemistry after dark adaptation \\
$\mathrm{F}_{0}{ }^{\prime}=\mathrm{F}_{0} /\left(\mathrm{F}_{\mathrm{v}} / \mathrm{F}_{\mathrm{m}}+\mathrm{F}_{0} / \mathrm{F}_{\mathrm{m}}{ }^{\prime}\right)$ & Minimum fluorescence after light adaptation \\
$\mathrm{F}_{\mathrm{v}}{ }^{\prime} / \mathrm{F}_{\mathrm{m}}{ }^{\prime}=\left(\mathrm{F}_{\mathrm{m}}{ }^{\prime}-\mathrm{F}_{0}{ }^{\prime}\right) / \mathrm{F}_{\mathrm{m}}{ }^{\prime}$, & Maximum quantum yield of PSII after light adaptation \\
$\mathrm{q}_{\mathrm{P}}=\left(\mathrm{F}_{\mathrm{m}}{ }^{\prime}-\mathrm{F}_{\mathrm{s}}\right) /\left(\mathrm{F}_{\mathrm{m}}{ }^{\prime}-\mathrm{F}_{0}{ }^{\prime}\right)$ & Proportion of open PSII reaction centers \\
$\mathrm{Y}_{(\mathrm{II})}=\left(\mathrm{F}_{\mathrm{m}}{ }^{\prime}-\mathrm{F}_{\mathrm{s}}\right) / \mathrm{F}_{\mathrm{m}}{ }^{\prime}$ & Effective quantum yield of PSII photochemistry \\
$\mathrm{Y}_{(\mathrm{NPQ})}=\mathrm{F}_{\mathrm{s}} / \mathrm{F}_{\mathrm{m}}{ }^{\prime}-\mathrm{F}_{\mathrm{s}} / \mathrm{F}_{\mathrm{m}}$ & Quantum yield of regulated energy dissipation in PSII via NPQ \\
$\mathrm{Y}_{(\mathrm{NO})}=\mathrm{F}_{\mathrm{s}} / \mathrm{F}_{\mathrm{m}}$ & Quantum yield of nonregulated energy dissipation in PSII \\
\hline
\end{tabular}



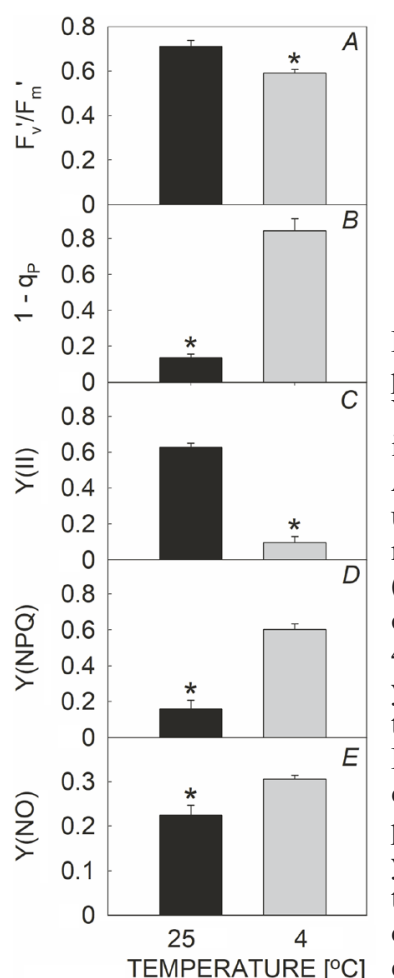

E effective quantum yield of PSII photochemistry; $\mathrm{Y}_{(\mathrm{NPO})}$ - quantum yield of regulated energy dissipation in PSII via NPQ; $\mathrm{Y}_{(\mathrm{NO})}-$ quantum yield of nonregulated

treatment on PSII and OEC. During the chilling treatment, the Chl fluorescence emission at the $\mathrm{J}$, I, and $\mathrm{P}$ levels $\left(\mathrm{F}_{\mathrm{J}}, \mathrm{F}_{\mathrm{I}}\right.$, and $\mathrm{F}_{\mathrm{P}}$ ) all decreased (Fig. $2 A$ ). The relative fluorescence intensity at $\mathrm{O}-\mathrm{J}$ level gradually increased during the chilling treatment (Fig. 2B), indicating the photodamage to donor side of PSII. Furthermore, the difference in relative Chl fluorescence intensity $\left(\Delta \mathrm{V}_{\mathrm{t}}\right)$ at $300 \mu \mathrm{s}$ (K-step) gradually increased during the chilling treatment (Fig. 2C), suggesting that this chilling-light stress caused significant photodamage to the OEC (Srivastava et al. 1997, Strasser 1997, Strasser et al. 2000, 2004; De Ronde et al. 2004, Li et al. 2009).

During the chilling-light treatment, $\mathrm{F}_{0}$ slightly increased with the increase in treatment time (Fig. $3 A$ ). Meanwhile, $\mathrm{F}_{\mathrm{m}}$ largely decreased. After chilling treatment for $6 \mathrm{~h}, \mathrm{~F}_{\mathrm{m}}$ decreased from 3.2 to 1.5 (Fig. $3 B$ ). Consequently, the maximum quantum yield of PSII after dark adaptation $\left(\mathrm{F}_{\mathrm{v}} / \mathrm{F}_{\mathrm{m}}\right)$ gradually decreased with the increase in chilling treatment time (Fig. 3C). As showed in Fig. $3 C, \mathrm{~F}_{\mathrm{v}} / \mathrm{F}_{\mathrm{m}}$ decreased from 0.83 to 0.50 after this chilling treatment for $6 \mathrm{~h}$. The decline in both $\mathrm{F}_{\mathrm{m}}$ and $\mathrm{F}_{\mathrm{v}} / \mathrm{F}_{\mathrm{m}}$ strongly indicated the severe PSII photoinhibition induced by this chillinglight stress. Furthermore, the relative $\mathrm{Chl}$ fluorescence intensity at $300 \mu \mathrm{s}\left(\mathrm{V}_{\mathrm{K}}\right)$ gradually increased during the chilling treatment (Fig. $4 A$ ), indicating that the extent of photodamage to OEC was accelerated with the increase in treatment time. Pooling the data obtained during chilling treatment, $\mathrm{F}_{\mathrm{v}} / \mathrm{F}_{\mathrm{m}}$ was strongly and negatively correlated with $\mathrm{V}_{\mathrm{K}}$ and $\mathrm{W}_{\mathrm{K}}$ (Fig. 4B,C), suggesting that photodamage to the OEC was significantly correlated with the total PSII photoinhibition.

Effect of methyl viologen on PSII photoinhibition: In order to examine whether additional ROS can accelerate

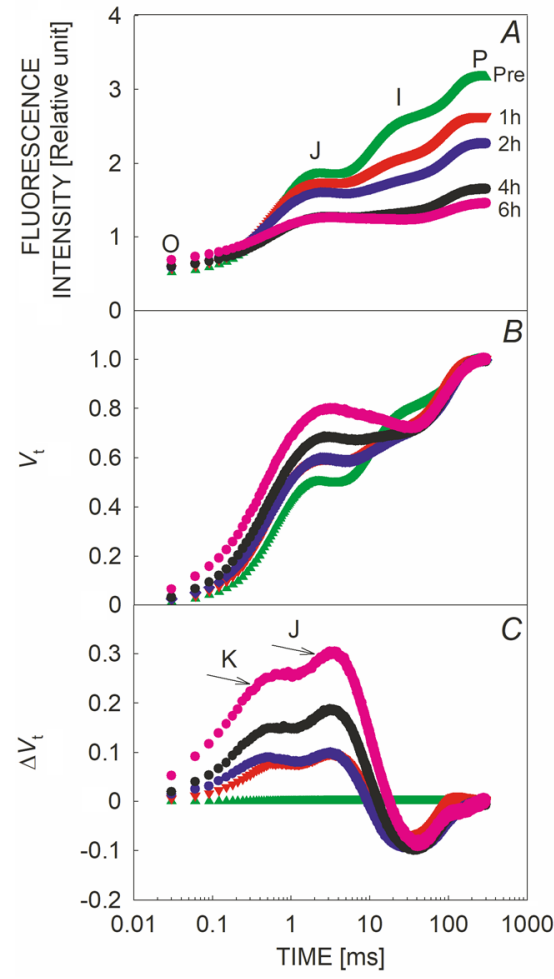

Fig. 2. Changes in chlorophyll $a$ fluorescence OJIP $(A)$, relative variable fluorescence at time $\mathrm{t}\left(\mathrm{V}_{\mathrm{t}}\right)(B)$, and the change in $\mathrm{V}_{\mathrm{t}}\left(\Delta \mathrm{V}_{\mathrm{t}}\right)$ $(C)$ in Dalbergia odorifera during the chilling treatment at $4^{\circ} \mathrm{C}$ under a light of $430 \mu \mathrm{mol}$ (photon) $\mathrm{m}^{-2} \mathrm{~s}^{-1} \cdot \mathrm{V}_{\mathrm{t}}=\left(\mathrm{F}_{\mathrm{t}}-\mathrm{F}_{0}\right) /\left(\mathrm{F}_{\mathrm{m}}-\mathrm{F}_{0}\right)$, $\Delta \mathrm{V}_{\mathrm{t}}=\left[\left(\mathrm{F}_{\mathrm{t}}-\mathrm{F}_{0}\right) /\left(\mathrm{F}_{\mathrm{m}}-\mathrm{F}_{0}\right)\right]_{\text {treatment }}-\left[\left(\mathrm{F}_{\mathrm{t}}-\mathrm{F}_{0}\right) /\left(\mathrm{F}_{\mathrm{m}}-\mathrm{F}_{0}\right)\right]_{\text {control. }}$. In this study, $\left[\left(\mathrm{F}_{\mathrm{t}}-\mathrm{F}_{0}\right) /\left(\mathrm{F}_{\mathrm{m}}-\mathrm{F}_{0}\right)\right]_{\text {control }}$ represents the value of $\left(\mathrm{F}_{\mathrm{t}}-\mathrm{F}_{0}\right) /$ $\left(\mathrm{F}_{\mathrm{m}}-\mathrm{F}_{0}\right)$ measured before chilling treatment. The average was calculated from four independent leaves.

PSII photoinhibition at chilling temperature, we determined the effect of MV on PSII photoinhibition during chilling treatment. MV promotes the production of superoxide anion radicals in the chloroplast stroma by accepting electrons from PSI. After treatment at $4^{\circ} \mathrm{C}$ for $2 \mathrm{~h}$ under a moderate light of $430 \mu \mathrm{mol}$ (photon) $\mathrm{m}^{-2} \mathrm{~s}^{-1}$, there was no significant difference in $\mathrm{F}_{\mathrm{v}} / \mathrm{F}_{\mathrm{m}}$ between MV-treated and $\mathrm{H}_{2} \mathrm{O}$-treated samples in shade leaves (Fig. 5). Therefore, the supplemental generation of ROS in the chloroplast stroma did not accelerate PSII photodamage in the shade leaves illuminated at chilling temperature.

\section{Discussion}

\section{Chilling-light stress induces photodamage to OEC and PSII}

In the present study, we examined the effect of chillinglight stress on the extent of photoinhibition of PSII and OEC. Our results indicated that chilling-light stress induced significant increase in the relative fluorescence intensity at $300 \mu \mathrm{s}\left(\mathrm{V}_{\mathrm{K}}\right)$ in the tropical tree species D. odorifera (Fig. 2). Because the K-step correlates with damage to the donor side of PSII (Strasser 1997, De Ronde et al. 2004, Strasser et al. 2004), and OEC is responsible for the splitting of water molecules and provides electrons 


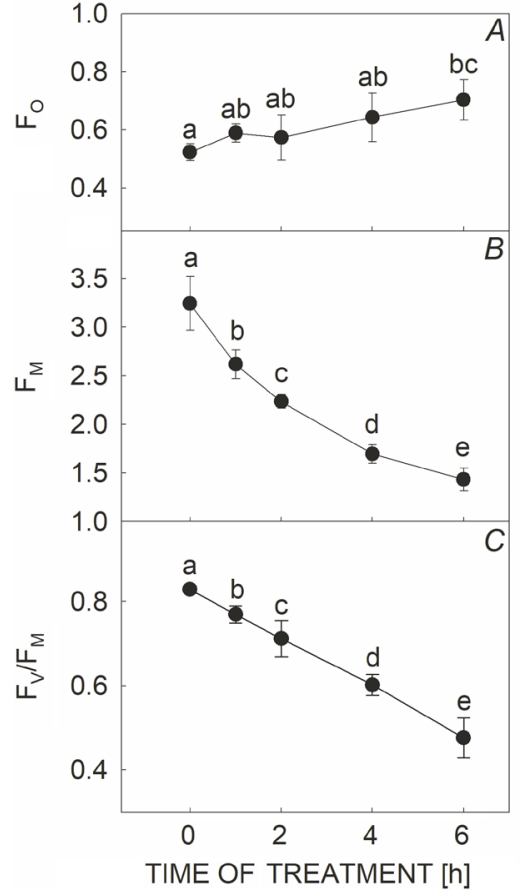

Fig. 3. Time course of minimum fluorescence $\left(\mathrm{F}_{0}\right)(A)$, maximum fluorescence $\left(\mathrm{F}_{\mathrm{m}}\right)(B)$, and maximum quantum yield of PSII $\left(\mathrm{F}_{\mathrm{v}} / \mathrm{F}_{\mathrm{m}}\right)(C)$ in Dalbergia odorifera during treatment at $4^{\circ} \mathrm{C}$ and $430 \mu$ mol(photon) $\mathrm{m}^{-2} \mathrm{~s}^{-1}$. Values are means $\pm \mathrm{SD}(n=4)$. Different letters indicate significant differences between different treatments.

to PSII reaction centers, the increase in $\mathrm{V}_{\mathrm{K}}$ indicated the photodamage to OEC (Huang et al. 2016b, Kalaji et al. 2018). Furthermore, with the increase in chilling treatment time, $V_{K}$ gradually increased, suggesting that the extent of photodamage to OEC was dependent on the total light energy absorbed by photosynthetic pigments. Although manganese compounds show very low light absorbance at visible light spectra (Hakala et al. 2005), this result indicated that the slight visual light energy absorbed by the manganese compounds was still sufficient to damage OEC.

During the chilling treatment, the decrease in $F_{v} / F_{m}$ was linearly correlated with treatment time course, indicating that the repair process was inhibited entirely at the chilling temperature of $4^{\circ} \mathrm{C}$, consistent with the result of Allakhverdiev and Murata (2004). As reported in previous study, the rate of PSII repair is largely dependent on the ATP synthesis of ATP via PSI and PSII (Allakhverdiev et al. 2005, Huang et al. 2018, Murata and Nishiyama 2018). At chilling temperature, the photosynthetic electron flow through PSII was largely reduced in the studied species D. odorifera (Fig. 1). Furthermore, the total electron transport rate through PSI was also reduced by the chilling temperature (Huang et al. 2011). Therefore, the chillinglight stress resulted in the inhibition of ATP synthesis, which in turn restricted the recovery of photodamaged PSII. Consequently, the rate of total PSII photoinhibition at chilling-light stress was mainly determined by the rate of photodamage.
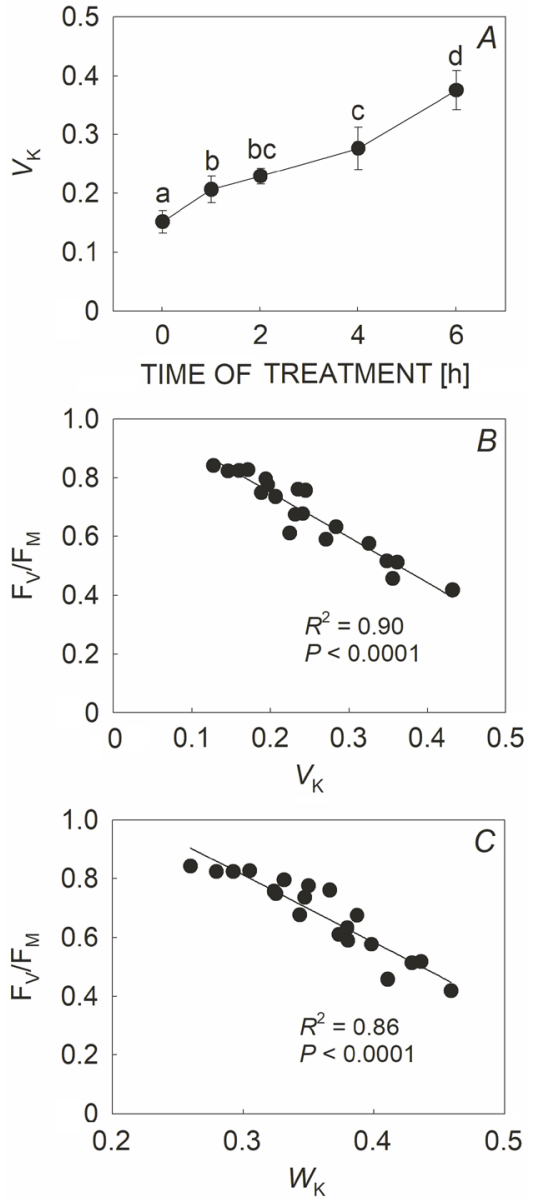

Fig. 4. Time course of the relative fluorescence intensity at $300 \mu \mathrm{s}$ $\left(\mathrm{V}_{\mathrm{K}}\right)$ in Dalbergia odorifera during the chilling treatment at $4^{\circ} \mathrm{C}$ and $430 \mu \mathrm{mol}\left(\right.$ photon) $\mathrm{m}^{-2} \mathrm{~s}^{-1}(A)$. Changes in maximum quantum yield of PSII $\left(\mathrm{F}_{\mathrm{v}} / \mathrm{F}_{\mathrm{m}}\right)$ as functions of $\mathrm{V}_{\mathrm{K}}(B)$ and the ratio of variable fluorescence $F_{K}$ to the amplitude $F_{J}-F_{0}\left(W_{K}\right)$ $(C)$ in Dalbergia odorifera during the chilling treatment. Values are means $\pm \mathrm{SD}(n=4)$. Different letters indicate significant differences between different treatments.

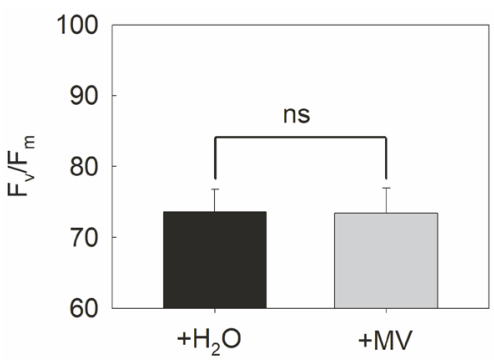

Fig. 5. Effect of methyl viologen (MV) on the decrease in maximum quantum yield of PSII $\left(\mathrm{F}_{\mathrm{v}} / \mathrm{F}_{\mathrm{m}}\right)$ induced by chilling and light treatment in the shade (10\% sunlight) leaves of Dalbergia odorifera. After treated with $300 \mu \mathrm{M}$ MV or water, leaf samples were illuminated at $4{ }^{\circ} \mathrm{C}$ for $2 \mathrm{~h}$ under $430 \mu \mathrm{mol}$ (photon) $\mathrm{m}^{-2} \mathrm{~s}^{-1}$. All values were expressed relative to the controls measured before the chilling treatment. Values are means $\pm \operatorname{SE}(n=4)$. ns - no significant difference. 
If the rate of photodamage to PSII was controlled by ROS, the rate of PSII photoinhibition would not be linearly correlated with the rate of photodamage of OEC, because ROS hardly cause oxidative photodamage to OEC (Hakala et al. 2005, Ohnishi et al. 2005). However, if the rate of photodamage of PSII is limited by the rate of photodamage of OEC, the decrease in $\mathrm{F}_{\mathrm{v}} / \mathrm{F}_{\mathrm{m}}$ would be linearly correlated with the increase in $\mathrm{V}_{\mathrm{K}}$. Interestingly, our present study indicated that $\mathrm{F}_{\mathrm{v}} / \mathrm{F}_{\mathrm{m}}$ was strongly negatively correlated with $\mathrm{V}_{\mathrm{K}}$ (Fig. $4 B$ ). This result suggested that the chillinginduced PSII photodamage in the studied species was mainly limited by the photodamage to OEC, but not by the ROS. Inactivation of OEC induces suppression of electron supply from water to $\mathrm{P}_{680}$, and then leads to high levels of $\mathrm{P}_{680}{ }^{+} \cdot$. Since $\mathrm{P}_{680}{ }^{+\bullet}$ is a strong oxidant, high levels of $\mathrm{P}_{680}{ }^{+\bullet}$ might damage the PSII reaction center (Takahashi and Murata 2008, Takahashi and Badger 2011). Therefore, our results indicated that photodamage to OEC is a ratelimiting step for chilling-induced photodamage of PSII for the studied tropical species, which provides new evidence to support the two-step scheme of photodamage of PSII over the excess-energy scheme.

\section{ROS did not aggravate PSII photodamage at chilling temperature}

During the chilling treatment, $\mathrm{Y}_{\text {(II) }}$ was largely inhibited and $\mathrm{Y}_{(\mathrm{NPQ})}$ gradually decreased (Fig. $1 C, D$ ), leading to the increase in $\mathrm{Y}_{(\mathrm{NO})}($ Fig. $1 E)$. $\mathrm{Y}_{(\mathrm{NO})}$ consists of nonphotochemical quenching due to photoinactivation of PSII and constitutive thermal dissipation that is very stable despite environmental stresses (Busch et al. 2009). Thus, the increase in $\mathrm{Y}_{(\mathrm{NO})}$ indicates an increase in production of ROS. With the increase in treatment time, ROS would be gradually accumulated. If ROS caused direct oxidative damage to PSII, the rate of photodamage would increase gradually with the increase in treatment time. In contrast, the decrease in $\mathrm{F}_{\mathrm{v}} / \mathrm{F}_{\mathrm{m}}$ was linearly correlated with the time course of chilling treatment (Fig. 3C). Therefore, these results suggest that ROS hardly caused direct oxidative photodamage to PSII at chilling-light stress for the studied tropical species.

We further examine the effect of ROS on PSII photoinhibition in shade leaves by adding MV. Since MV promotes electrons from PSI to $\mathrm{O}_{2}$, the production of ROS should be much greater in the MV-treated samples than that of the $\mathrm{H}_{2} \mathrm{O}$-treated samples. If the chilling-induced photodamage to PSII in the studied tropical tree species can be affected by ROS, the supplemental addition of ROS should aggravate PSII photodamage. In fact, the MV-treated samples did not show greater PSII photoinhibition than the $\mathrm{H}_{2} \mathrm{O}$-treated samples (Fig. 5). It should be noted that MV also abolish cyclic electron flow around PSI. In order to exclude the effect of CEF in the shade leaves of $D$. odorifera, we examined the CEF activity and found that the shade leaves showed much lower CEF activity than that of sun leaves (data not shown). As a result, the effect of MV on PSII photodamage in the shade leaves is mainly attributed to the additional generation of ROS (Takahashi et al. 2009). Our results indicated that
ROS did not aggravate PSII photodamage in shade leaves of the studied species, which again supports the two-step scheme of PSII photodamage (Murata et al. 2012).

In summary, we found that chilling temperature associated with moderate light intensity significantly induced photodamage to the OEC in a tropical tree species $D$. odorifera. The photodamage to OEC was a ratelimiting step for chilling-induced PSII photoinhibition. Furthermore, supplemental production of reactive oxygen species by infiltration with methyl viologen did not aggravate PSII photoinhibition. These results strongly suggested that the chilling-induced PSII photoinhibition in the studied tropical species was attributed to the two-step photodamage model.

\section{References}

Allakhverdiev S.I., Murata N.: Environmental stress inhibits the synthesis de novo of proteins involved in the photodamagerepair cycle of photosystem II in Synechocystis sp. PCC 6803.BBA-Bioenergetics 1657: 23-32, 2004.

Allakhverdiev S.I., Nishiyama Y., Takahashi S. et al.: Systematic analysis of the relation of electron transport and ATP synthesis to the photodamage and repair of photosystem II in Synechocystis. - Plant Physiol. 137: 263-273, 2005.

Antal T.K., Lo W., Armstrong W.H., Tyystjärvi E.: Illumination with ultraviolet or visible light induces chemical changes in the water-soluble manganese complex, $\left[\mathrm{Mn}_{4} \mathrm{O}_{6}(\text { bpea })_{4}\right] \mathrm{Br}_{4}$. Photochem. Photobiol. 85: 663-668, 2009.

Barth C., Krause G.H.: Inhibition of photosystems I and II in chilling-sensitive and chilling-tolerant plants under light and low-temperature stress. - Z. Naturforsch. 54: 645-657, 1999.

Busch F., Hunter N.P.A., Ensminger I.: Biochemical constrains limit the potential of the photochemical reflectance index as a predictor of effective quantum efficiency of photosynthesis during the winter spring transition in Jack pine seedlings. Funct. Plant Biol. 36: 1016-1026, 2009.

Chow W.S., Aro E.M.: Photoinactivation and mechanisms of recovery. - In: Wydrzynski T., Satoh K. (ed.): Photosystem II: The Light-Driven Water: Plastoquinone Oxidoreductase. Advances in Photosynthesis and Respiration. Pp. 627-648. Springer, Dordrecht 2005.

Dąbrowski P., Baczewska A.H., Pawluśkiewicz B. et al.: Prompt chlorophyll $a$ fluorescence as a rapid tool for diagnostic changes in PSII structure inhibited by salt stress in Perennial ryegrass. - J. Photoch. Photobio. B 157: 22-31, 2016.

Dąbrowski P., Kalaji M.H., Baczewska A.H. et al.: Delayed chlorophyll $a$ fluorescence, MR 820, and gas exchange changes in perennial ryegrass under salt stress. - J. Lumin. 183: 322-333, 2017.

Dąbrowski P., Pawluśkiewicz B., Baczewska A.H. et al.: Chlorophyll $a$ fluorescence of perennial ryegrass (Lolium perenne L.) varieties under long term exposure to shade.-Zemdirbyste 102: 305-312, 2015.

De Ronde J.A., Cress W.A., Krüger G.H.J. et al.: Photosynthetic response of transgenic soybean plants, containing an Arabidopsis P5CR gene, during heat and drought stress. J. Plant Physiol. 161: 1211-1224, 2004.

Genty B., Briantais J.M., Baker N.R.: The relationship between the quantum yield of photosynthetic electron transport and quenching of chlorophyll fluorescence. - BBA-Gen. Subjects 990: 87-92, 1989.

Hakala M., Tuominen I., Keränen M. et al.: Evidence for the role of the oxygen-evolving manganese complex in photoinhibition 
of photosystem II. - BBA-Bioenergetics 1706: 68-80, 2005.

Hendrickson L., Furbank R.T., Chow W.S.: A simple alternative approach to assessing the fate of absorbed light energy using chlorophyll fluorescence. - Photosynth. Res. 82: 73-81, 2004.

Huang W., Yang Y.J., Hu H., Zhang S.B.: Moderate photoinhibition of photosystem II protects photosystem I from photodamage at chilling stress in tobacco leaves. - Front. Plant Sci. 7: 182, $2016 \mathrm{a}$.

Huang W., Yang Y.J., Hu H. et al.: Evidence for the role of cyclic electron flow in photoprotection for oxygen-evolving complex. - J. Plant Physiol. 194: 54-60, 2016b.

Huang W., Yang Y.J., Zhang S.B., Liu T.: Cyclic electron flow around photosystem I promotes ATP synthesis possibly helping the rapid repair of photodamaged photosystem II at low light. - Front. Plant Sci. 9: 239, 2018.

Huang W., Zhang S.B., Cao K.F.: The different effects of chilling stress under moderate illumination on photosystem II compared with photosystem I and subsequent recovery in tropical tree species. - Photosynth. Res. 103: 175-182, 2010 a.

Huang W., Zhang S.B., Cao K.F.: Stimulation of cyclic electron flow during recovery after chilling-induced photoinhibition of PSII. - Plant Cell Physiol. 51: 1922-1928, 2010b.

Huang W., Zhang S.B., Cao K.F.: Cyclic electron flow plays an important role in photoprotection of tropical trees illuminated at temporal chilling temperature. - Plant Cell Physiol. 52: 297-305, 2011.

Huang W., Zhang S.B., Xu J.C., Liu T.: Plasticity in roles of cyclic electron flow around photosystem I at contrasting temperatures in the chilling-sensitive plant Calotropis gigantea. - Environ. Exp. Bot. 141: 145-153, 2017.

Kalaji H.M., Račková L., Paganová V. et al.: Can chlorophyll-a fluorescence parameters be used as bio-indicators to distinguish between drought and salinity stress in Tilia cordata Mill? - Environ. Exp. Bot. 152: 149-157, 2018.

Kramer D.M., Johnson G., Kiirats O., Edwards G.E.: New fluorescence parameters for the determination of $\mathrm{Q}_{\mathrm{A}}$ redox state and excitation energy fluxes. - Photosynth. Res. 79: 209218, 2004

Krieger-Liszkay A., Fufezan C., Trebst A.: Singlet oxygen production in photosystem II and related protection mechanism. Photosynth. Res. 98: 551-564, 2008.

Krieger-Liszkay A., Kos P.B., Hideg E.: Superoxide anion radicals generated by methylviologen in photosystem I damage photosystem II. - Physiol. Plantarum 142: 17-25, 2011.

Li P.M., Cheng L.L., Gao H.Y. et al.: Heterogeneous behavior of PSII in soybean (Glycine max) leaves with identical PSII photochemistry efficiency under different high temperature treatments. - J. Plant Physiol. 166: 1607-1615, 2009.

Mathur S., Kalaji H.M., Jajoo A.: Investigation of deleterious effects of chromium phytotoxicity and photosynthesis in wheat plant. - Photosynthetica 54: 185-192, 2016.

Murata N., Allakhverdiev S.I., Nishiyama Y.: The mechanism of photoinhibition in vivo: Re-evaluation of the roles of catalase, $\alpha$-tocopherol, non-photochemical quenching, and electron transport. - BBA-Bioenergetics 1817: 1127-1133, 2012.

Murata N., Nishiyama Y.: ATP is a driving force in the repair of photosystem II during photoinhibition. - Plant Cell Environ. 41: 285-299, 2018.

Murata N., Takahashi S., Nishiyama Y., Allakhverdiev S.I.: Photoinhibition of photosystem II under environmental stress. - BBA-Bioenergetics 1767: 414-421, 2007.

Nishiyama Y., Allakhverdiev S.I., Murata N.: Inhibition of the repair of photosystem II by oxidative stress in cyanobacteria. Photosynth. Res. 84: 1-7, 2005.

Nishiyama Y., Allakhverdiev S.I., Murata N.: A new paradigm for the action of reactive oxygen species in the photoinhibition of photosystem II. - BBA-Bioenergetics 1757: 742-749, 2006.

Nishiyama Y., Allakhverdiev S.I., Murata N.: Protein synthesis is the primary target of reactive oxygen species in the photoinhibition of photosystem II. - Physiol. Plantarum 142: 35-46, 2011.

Nishiyama Y., Allakhverdiev S.I., Yamamoto H. et al.: Singlet oxygen inhibits the repair of photosystem II by suppressing the translation elongation of the D1 protein in Synechocystis sp. PCC 6803. - Biochemistry 43: 11321-11330, 2004.

Nishiyama Y., Yamamoto H., Allakhverdiev S.I. et al.: Oxidative stress inhibits the repair of photodamage to the photosynthetic machinery. - EMBO J. 20: 5587-5594, 2001.

Oguchi R., Terashima I., Kou J., Chow W.S.: Operation of dual mechanisms that both lead to photoinactivation of photosystem II in leaves by visible light. - Physiol. Plantarum 142: 47-55, 2011.

Ohnishi N., Allakhverdiev S.I., Takahashi S. et al.: Two-step mechanism of photodamage to photosystem II: Step one occurs at the oxygen-evolving complex and step two occurs at the photochemical reaction center. - Biochemistry 44: 8494$8499,2005$.

Okada S., Ikeuchi M., Yamamoto N. et al.: Selective and specific cleavage of the D1 and D2 proteins of photosystem II by exposure to singlet oxygen: Factors responsible for the susceptibility to cleavage of the proteins. - BBA-Bioenergetics 1274: 73-79, 1996.

Oxborough K., Baker N.R.: Resolving chlorophyll $a$ fluorescence images of photosynthetic efficiency into photochemical and non-photochemical components - calculation of $\mathrm{q}_{\mathrm{p}}$ and $\mathrm{F}_{\mathrm{v}}{ }^{\prime} / \mathrm{F}_{\mathrm{m}}{ }^{\prime}$ without measuring $\mathrm{F}_{0}{ }^{\prime}$. - Photosynth. Res. 54: 135-142, 1997.

Srivastava A., Guisse B., Greppin H., Strasser R.J.: Regulation of antenna structure and electron transport in PSII of Pisum sativum under elevated temperature probed by the fast polyphasic chlorophyll $a$ fluorescence transient: OKJIP. BBA-Bioenergetics 1320: 95-106, 1997.

Strasser B.J.: Donor side capacity of photosystem II probed by chlorophyll $a$ fluorescence transients. - Photosynth. Res. 52: 147-155, 1997.

Strasser R.J., Srivastava A., Tsimilli-Michael M.: The fluorescence transient as a tool to characterize and screen photosynthetic samples. - In: Yunus M., Pathre U., Mohanty P. (ed.): Probing Photosynthesis: Mechanism, Regulation and Adaptation. Pp. 445-483. CRC Press, New York 2000.

Strasser R.J., Tsimilli-Michael M., Srivastava A.: Analysis of the chlorophyll $a$ fluorescence transient. - In: Papageorgiou G.C., Govindjee (ed.): Chlorophyll $a$ Fluorescence: A Signature of Photosynthesis. Advances in Photosynthesis and Respiration. Pp. 321-362. Springer, Dordrecht 2004.

Swoczyna T., Kalaji H.M., Pietkiewicz S. et al.: Photosynthetic apparatus efficiency of eight tree taxa as an indicator of their tolerance to urban environment. - Dendrobiology 63: 65-75, 2010.

Takahashi S., Badger M.R.: Photoprotection in plants: a new light on photosystem II damage. - Trends. Plant Sci. 16: 5359, 2011.

Takahashi S., Milward S.E., Fan D.Y. et al.: How does cyclic electron flow alleviate photoinhibition in Arabidopsis? - Plant Physiol. 149: 1560-1567, 2009.

Takahashi S., Murata N.: How do environmental stresses accelerate photoinhibition? - Trend Plant Sci. 13: 178-182, 2008.

Telfer A., Dhami S., Bishop S.M. et al:: $\beta$-carotene quenches singlet oxygen formed by isolated photosystem II reaction centers. - Biochemistry 33: 14469-14474, 1994.

Tyystjärvi E.: Photoinhibition of photosystem II and photodamage 
of the oxygen evolving manganese cluster. - Coordin. Chem. Rev. 252: 361-376, 2008.

Vass I.: Role of charge recombination processes in photodamage and photoprotection of the photosystem II complex. - Physiol. Plantarum 142: 6-16, 2011.

Vass I.: Molecular mechanisms of photodamage in the photosystem II complex. - BBA-Bioenergetics 1817: 209$217,2012$.

Vass I., Styring S., Hundal T. et al.: Reversible and irreversible intermediates during photoinhibition of photosystem II: Stable reduced $\mathrm{Q}_{\mathrm{A}}$ species promote chlorophyll triplet formation. P. Natl. Acad. Sci. USA 89: 1408-1412, 1992.

Yang Y.J., Chang W., Huang W. et al.: The effects of chillinglight stress on photosystems I and II in three Paphiopedilum species. - Bot. Stud. 58: 53, 2017.
Yang Y.J., Zhang S.B., Huang W.: Chloroplastic ATP synthase alleviates photoinhibition of photosystem I in tobacco illuminated at chilling temperature. - Front. Plant Sci. 9: 1648,2018

Zavafer A., Cheah M.H., Hillier W. et al:: Photodamage to the oxygen evolving complex of photosystem II by visible light. Sci. Rep.-UK 5: 16363, 2015.

Zavafer A., Koinuma W., Chow W.S. et al.: Mechanism of photodamage of the oxygen evolving Mn cluster of photosystem II by excessive light energy. - Sci. Rep.-UK 7: 7604, 2017.

Zsiros O., Allakhverdiev S.I., Higashi S. et al.: Very strong UV-A light temporally separates the photoinhibition of photosystem II into light-induced inactivation and repair. BBA-Bioenergetics 1757: 123-129, 2006.

(C) The authors. This is an open access article distributed under the terms of the Creative Commons BY-NC-ND Licence. 